\title{
Application of a continuum damage mechanics (CDM)-based model for predicting formability of warm formed aluminium alloy
}

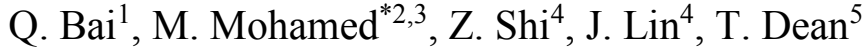 \\ ${ }^{1}$ Key Laboratory for Precision and Non-traditional Machining Technology of Ministry of Education, \\ Dalian University of Technology, Dalian 116024, China \\ ${ }^{2}$ Advanced Forming Research Centre (AFRC), Strathclyde University, Glasgow, PA4 9LJ \\ ${ }^{3}$ Department of Mechanical Engineering, Faculty of Engineering, Helwan University, Helwan, Egypt \\ ${ }^{4}$ Department of Mechanical Engineering, Imperial College London, London SW7 2AZ, UK \\ ${ }^{5}$ School of Mechanical Engineering, University of Birmingham, Birmingham B15 2TT, UK
}

\begin{abstract}
Predicting formability of sheet metal in warm forming condition is a challenge since warm forming is a thermo-mechanical process, and formability is varied with temperature and strain rate. Current standard forming limit curves (FLCs) which have been established for fixed values of temperatures and strain rates cannot be used directly to predict the formability of sheet metal in warm/hot forming processes. In this paper a series of experiment were carried out to establish FLCs for AA5754 at a temperature range of $200^{\circ} \mathrm{C}-300^{\circ} \mathrm{C}$ and a forming rate of $20 \mathrm{~mm} / \mathrm{s}-300 \mathrm{~mm} / \mathrm{s}$ using Argus system. Based on a set of continuum damage mechanics (CDM)-based theories, the constitutive model is implemented in Ls-Dyna user subroutine. FE result of strain distribution was compared with the experimental result from Argus system in terms of different strain paths. FE results have a good agreement with the experimental results, which indicates the FE model developed can be used to predict formability for warm forming process.
\end{abstract}

Keywords: Aluminium alloy; Forming limit curves; Major strain; Continuum damage mechanics (CDM); FE simulation.

\footnotetext{
${ }^{*}$ Corresponding author. Tel.: +44 (0) 7712155969

E-mail address: Dr. Mohamed Mohamed (Mohamed.mohamed@,strath.ac.uk)
} 


\section{Introduction}

Aluminium alloy sheet components are an important contribution to light-weight vehicles due to their high strength to weight ratio [1]. However a major drawback for aluminium alloy sheet is its low formability at ambient temperature compared with steels [2]. Using hot/warm forming methods, the formability of aluminium alloys can be improved. The ductility of these alloys increases with temperature, and generally is enhanced by low deformation speed [3]. However, it is a fact that the ductility of some aluminium alloys can be enhanced by raising deformation speed (AA6082 for example) [4]. Therefore, characterising the aluminium alloy formability at elevated temperatures and for a wide range of strain rates is crucial for the wider use of elevated temperature aluminium sheet forming processes [5-7].

One common means for evaluating sheet metal formability is the Forming Limit Diagram (FLD). FLDs have been extensively adopted in experimental and numerical investigations. In the FLD, Forming Limit Curves (FLCs) are used to determine the likely occurrence of failure, for given strain conditions $[8,9]$. They represent the limit strains for different strain paths in the principal strain space and are widely used for formability simulation in metal forming process. Many researchers are concerned with the determination of FLCs both experimentally and theoretically, and various testing methods are used to obtain experimental FLCs at room temperature $[10,11]$. Two of the most commonly used test methods are the Marciniak type test [12] and Nakajima type test [13]. Different geometries and widths of test-piece have been used by different researchers, when using these tests, to produce different strain states, from uniaxial to plane strain, to equibiaxial tension.

Due to the development of warm/hot forming processes for aluminium alloys, some efforts have been made to determine FLCs of aluminium alloys at elevated temperatures. However, 
current standard FLC relating to fixed values of temperature and strain rate cannot be used directly to predict the forming limit of aluminium sheet in warm/hot forming processes, since temperature and strain rate may be changed during a forming process $[14,15]$. Therefore, the conventional FLD is not an accurate method to predict the formability of the sheet metal forming at elevated temperature. Lin et al. $[16,17]$ developed s set of plane-stress continuum damage mechanics (CDM)-based viscoplastic constitutive equations to predict the shapes of FLCs for AA5754 at a temperature range of $350-550{ }^{\circ} \mathrm{C}$; however, the determination of the parameters and application in that model were not presented. In this paper the CDM-based constitutive model is introduced, based on fixed forming temperatures and forming rates. In this constitutive model, the fracture and forming limit are indicated by damage evolution, which may be summed over a range of changing temperature and strain rate; therefore, formability in a regime of changing temperature and strain rate can be predicted.

In this paper, an experimental procedure to establish FLCs for an aluminium alloy at elevated temperatures are presented and a set of continuum damage mechanics (CDM)-based constitutive equations describing viscoplastic damage are presented. Material parameters in this model is determined for a temperature range of $200-300{ }^{\circ} \mathrm{C}$ and a strain rate of 0.001 $1.0 \mathrm{~s}^{-1}$. A finite element (FE) model is developed, and the set of constitutive equations was integrated with this FE model via user-defined subroutine, and this FE model was applied to simulate a dome forming test in this paper. The FE model is validated by comparing predicted strain distributions with the experimental results for different strain paths.

\section{Experimental Programme}

Test-pieces were produced from commercial sheet alloy AA5754 supplied by Novelis UK Ltd. The chemical composition are listed in Table 1. Two sets of experimental data were used to calibrate the continuum viscoplastic damage model: stress-strain data from isothermal uniaxial 
tensile tests and FLD data from isothermal dome forming tests. Firstly, tensile tests were conducted at warm forming temperatures, within a range of $200^{\circ} \mathrm{C}-300^{\circ} \mathrm{C}$, and at strain rates within a range of 0.001-10 s-1. The tests were conducted within a furnace in which the temperature deviation in the test-piece is around $5^{\circ} \mathrm{C}$ in a range of $200^{\circ} \mathrm{C}-300^{\circ} \mathrm{C}$. The strain fields were obtained by means of a non-contacting optical deformation measuring system (ARAMIS system) $[16,18]$.

Table 1. The chemical composition of AA5754.

\begin{tabular}{|c|c|c|c|c|c|c|c|c|c|}
\hline Element & $\mathrm{Si}$ & $\mathrm{Fe}$ & $\mathrm{Cu}$ & $\mathrm{Mn}$ & $\mathrm{Mg}$ & $\mathrm{Cr}$ & $\mathrm{Zn}$ & $\mathrm{Ti}$ & $\mathrm{Al}$ \\
\hline $\mathbf{W t} \%$ & 0.08 & 0.16 & 0.004 & 0.45 & 3.2 & 0.001 & 0.01 & 0.02 & $\mathrm{Bal}$. \\
\hline
\end{tabular}

Secondly, the formability (dome forming) tests were carried out in the same furnace at various temperatures up to a maximum of $300^{\circ} \mathrm{C}$, a temperature deviation of $5^{\circ} \mathrm{C}$ was found in the testpiece, and forming speeds ranging from $20-300 \mathrm{~mm} / \mathrm{s}$. The GOM-ARGUS system was employed for measuring surface strain using pre-applied grids, and for determining limit strains according to the ISO 12004-2:2008 standard. The geometry of the test-piece was a circular blank with a central parallel edged waist, as shown in Figure 1. The rolling direction of the material was parallel to the longitudinal axis of the waist. A hemispherical punch was used with a diameter of $80 \mathrm{~mm}$. Different widths of waist (W) were used to achieve different strain paths as shown in Table 1. 


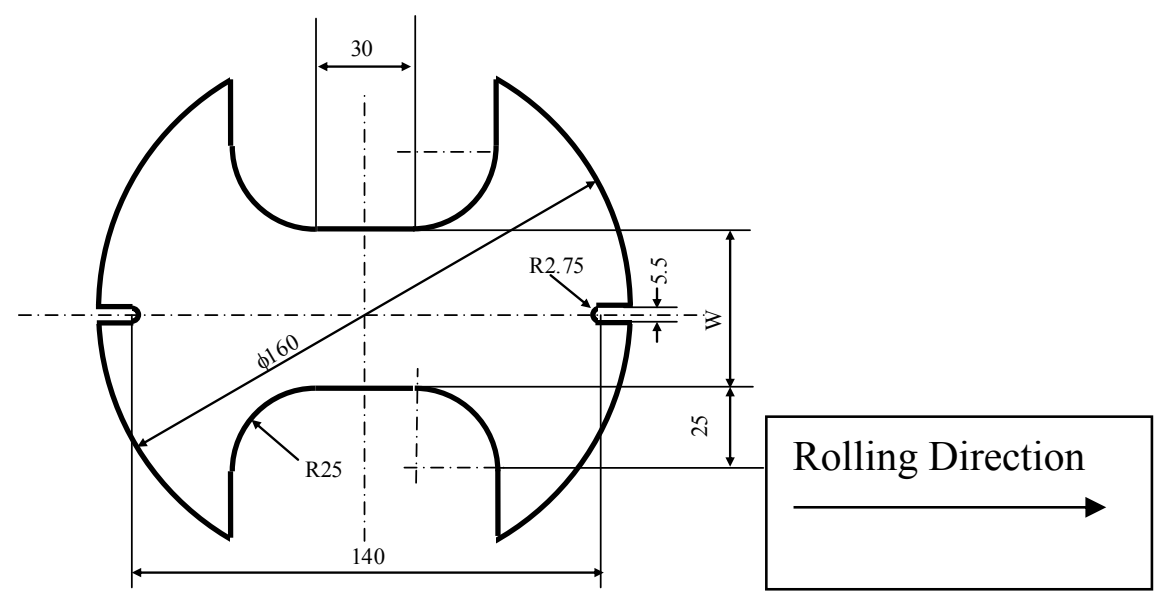

Figure 1. Blank geometry for Nakajima type tests (ISO 12004-2:2008) for Al alloys.

Table 1. Blank geometries for different stress state $\left(D_{p}\right.$ is the diameter of the punch.)

\begin{tabular}{|c|c|c|c|}
\hline Geometry No. & Test Type & W $(\mathbf{m m})$ & $\mathbf{W}_{\mathbf{1}} \mathbf{D}_{\mathbf{p}}$ \\
\hline $\mathbf{1}$ & Uniaxial Tension & 24 & 0.3 \\
\hline $\mathbf{2}$ & Close to plane strain & 64 & 0.8 \\
\hline $\mathbf{3}$ & Plane Strain & 80 & 1 \\
\hline $\mathbf{4}$ & Close to plane strain & 88 & 1.1 \\
\hline $\mathbf{5}$ & Between No.4 and 6 & 120 & 1.5 \\
\hline $\mathbf{6}$ & Equiaxial Tension & 160 & 2.0 \\
\hline
\end{tabular}

In order to use the GOM ARGUS system to analyse the strain after forming, a grid of $0.75 \mathrm{~mm}$ diameter circular dots with $1.5 \mathrm{~mm}$ centre-to-centre spacing was etched electrochemically. Nakajima type formability tests were conducted, using the tool set shown in Figure 2, mounted inside an oven on a $250 \mathrm{KN}$ hydraulic press. The tool set consisted of a hemispherical punch fixed to the bottom plate, which was stationary during tests. The blank holder, upper die and tests-pieces were driven downwards by the press. The lubricant of Hi-Temp MSL Grease (Omega 35), which can resist temperature up to $700{ }^{\circ} \mathrm{C}$, were pre-applied to the central area of 
the specimens to reduce the friction effect. Formability tests were carried out within a temperature range of $200{ }^{\circ} \mathrm{C}-300{ }^{\circ} \mathrm{C}$, and a forming speed range of $20 \mathrm{~mm} / \mathrm{s}-300 \mathrm{~mm} / \mathrm{s}$.

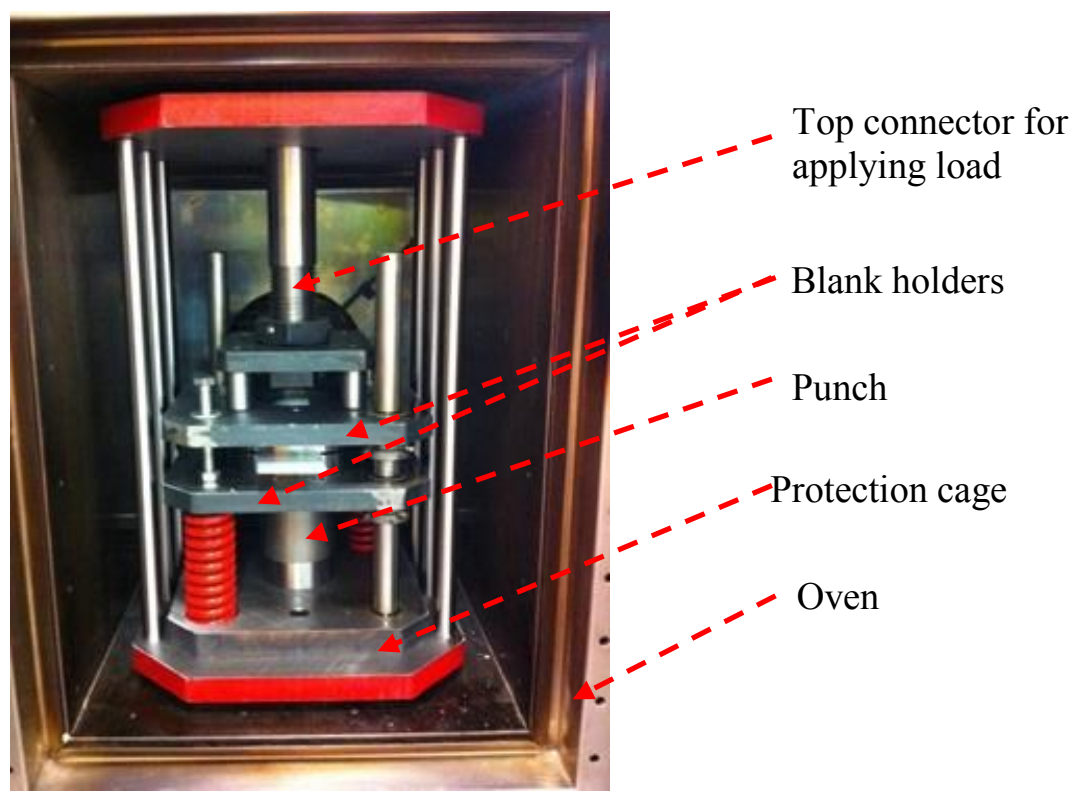

Figure 2. Dome forming tool set inside an oven

\section{Experimental results}

\subsection{Tensile tests}

Figure 3 shows the effect of strain rate on the flow stress of AA5754 at different testing temperatures. It is noticed from the results that the flow stress level increases with increasing strain rate and the ductility is found to decrease with increasing strain rate. With increase of temperature, ductility is increased, and flow stress is decreased. At higher temperatures and lower strain rates the flow stress is nearly independent of strain, i.e. no significant work hardening can be observed. The results indicate that dynamic recovery takes place. Towards the end of deformation the flow stress decreases due to damage softening, which dominates until final failure. 

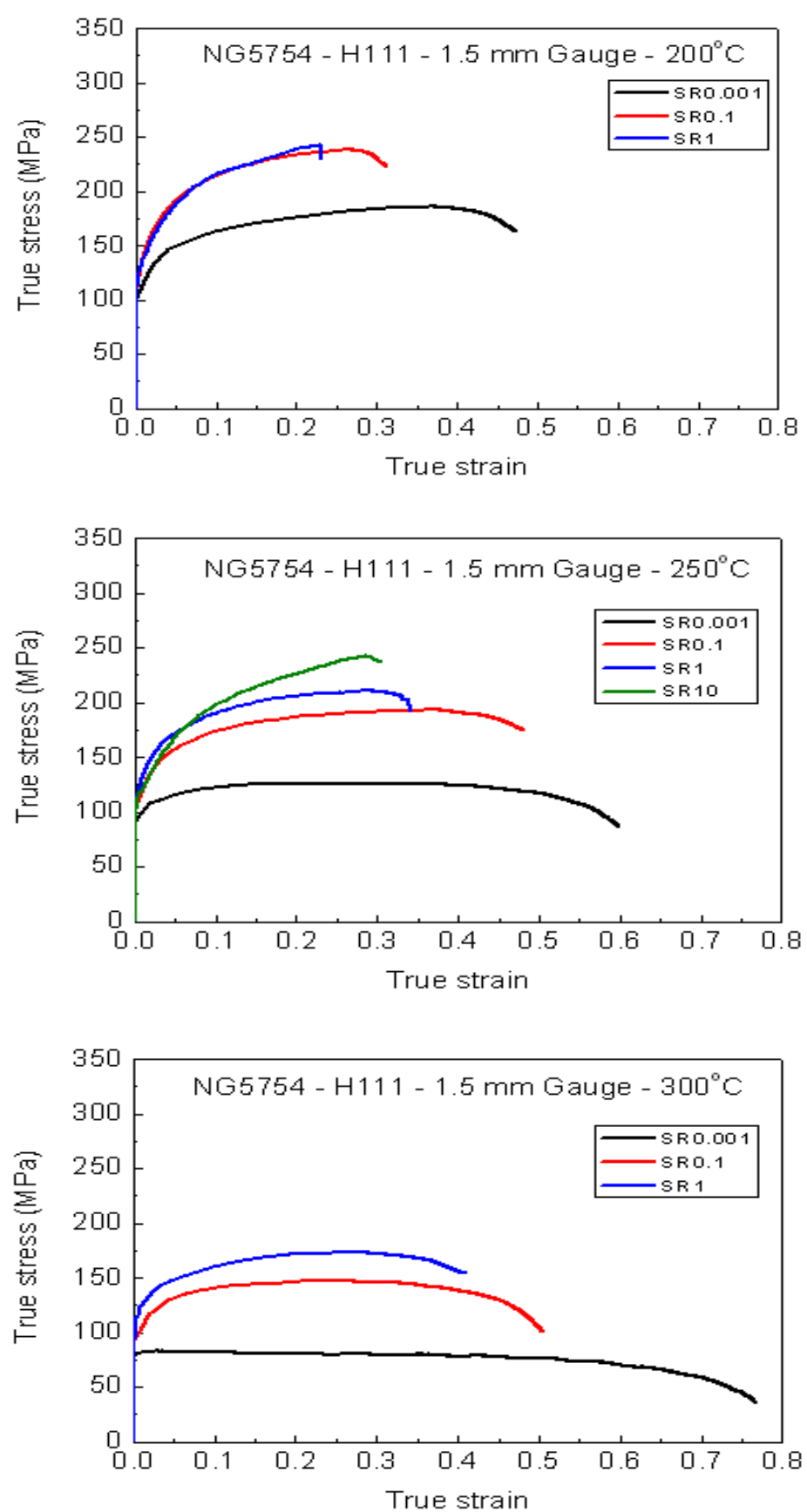

Figure 3 Effect of strain rate on the flow stress of AA5754 at different temperatures. Data from uniaxial tensile tests.

\subsection{Formability test results}

Figure 4(a) shows test-pieces of AA5754 formed at a temperature of $250{ }^{\circ} \mathrm{C}$ and a forming speed of $20 \mathrm{~mm} / \mathrm{s}$. Since it is difficult to eliminate friction during forming at elevated temperatures, some fractures are not located at the centre of a test-piece but they all are within an acceptable distance from it. (According to ISO 12004-2:2008 Standard the FLC test is 
considered to be valid when fracture occurs within a distance less than $15 \%$ of the punch diameter away from the apex of the dome.)

Figure4(b) illustrates a comparison of normalized thickness variation $\left(\mathrm{t} / \mathrm{t}_{0}\right)$ in directions relative to that of rolling, for equibiaxial strain states, at a temperature of $250{ }^{\circ} \mathrm{C}$ and a forming speed of $20 \mathrm{~mm} / \mathrm{s}$, where $t$ and $t_{0}$ are the current and initial thickness. It is observed that the thickness variation of the specimen is not significantly dependent on direction [3].

A GOM-ARGUS system was used to process the strain profiles. Minor and major strains were obtained by using inverse parabolic fittings [15]. By analysing test-pieces with different geometries, data for different strain paths were determined and hence an FLC obtained. Figure 4 shows FLCs for different temperatures at a forming speed of $75 \mathrm{~mm} / \mathrm{s}$, and different forming speeds at a temperature of $250^{\circ} \mathrm{C}$. As shown by the symbols in Figure 5(a), formability increases with increasing temperature as evidenced by the increase of the FLCs along the major strain axis. The increase is more significant at high temperature. The increase in formability from $250{ }^{\circ} \mathrm{C}$ to $300^{\circ} \mathrm{C}$ is about twice the increase from $200{ }^{\circ} \mathrm{C}$ to $250{ }^{\circ} \mathrm{C}$ in the plane strain region. As temperature increases, the V-shape of the FLCs appears to flatten, showing that the effect of the minor strain on formability reduced. As shown by the symbols in Figure 5(b), the forming limit increases with decreasing forming speed, suggusting that the best ductilicy lies at low speeds form warm forming. It can be seen that when speed decreases from $300 \mathrm{~mm} / \mathrm{s}$ to $75 \mathrm{~mm} / \mathrm{s}$, the forming limit increases in the plane strain region and the FLC is flatter. Signifincant improvement in forming limit is observed from $250{ }^{\circ} \mathrm{C}$ to $300{ }^{\circ} \mathrm{C}$.

(a) 

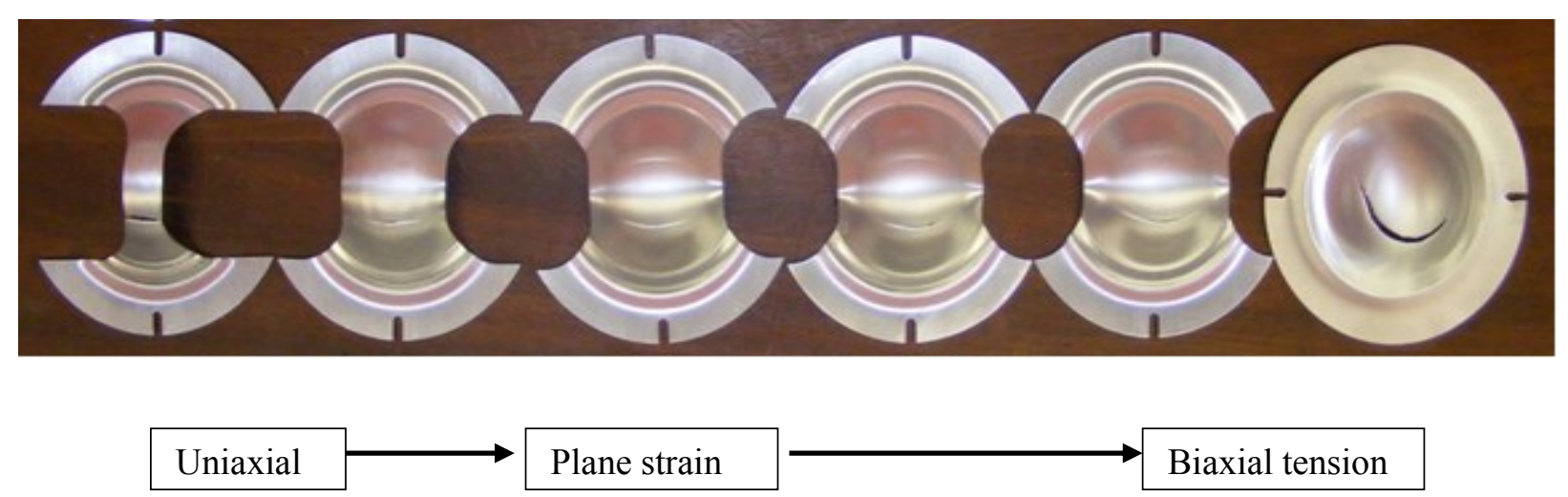

(b)

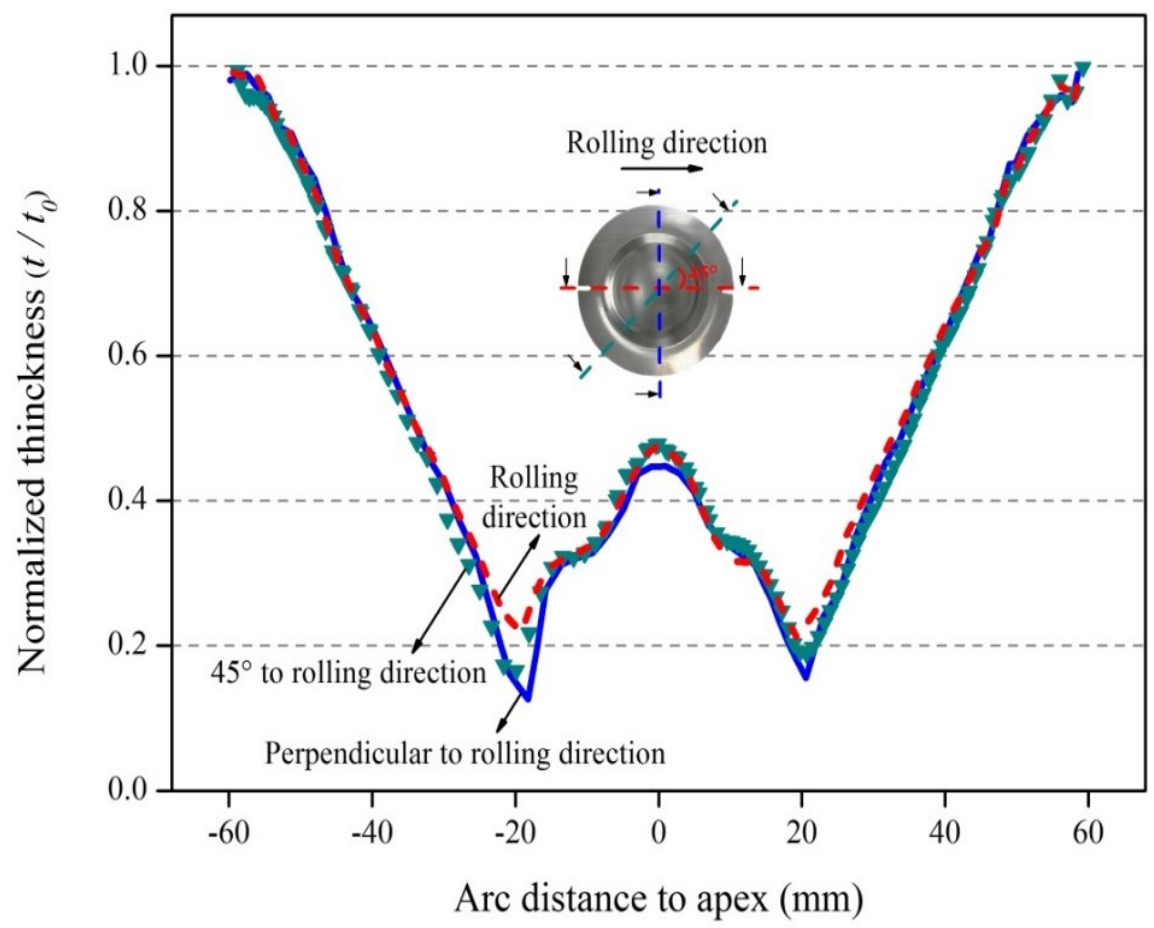

Figure 4. (a)Test-pieces of AA5754 formed at a temperature of $250{ }^{\circ} \mathrm{C}$ and a forming speed of $20 \mathrm{~mm} / \mathrm{s}$. (b) Comparison of normalized thickness variation in different directions for biaxial tension test-piece at $250{ }^{\circ} \mathrm{C}$ with a forming speed of $20 \mathrm{~mm} / \mathrm{s}$;

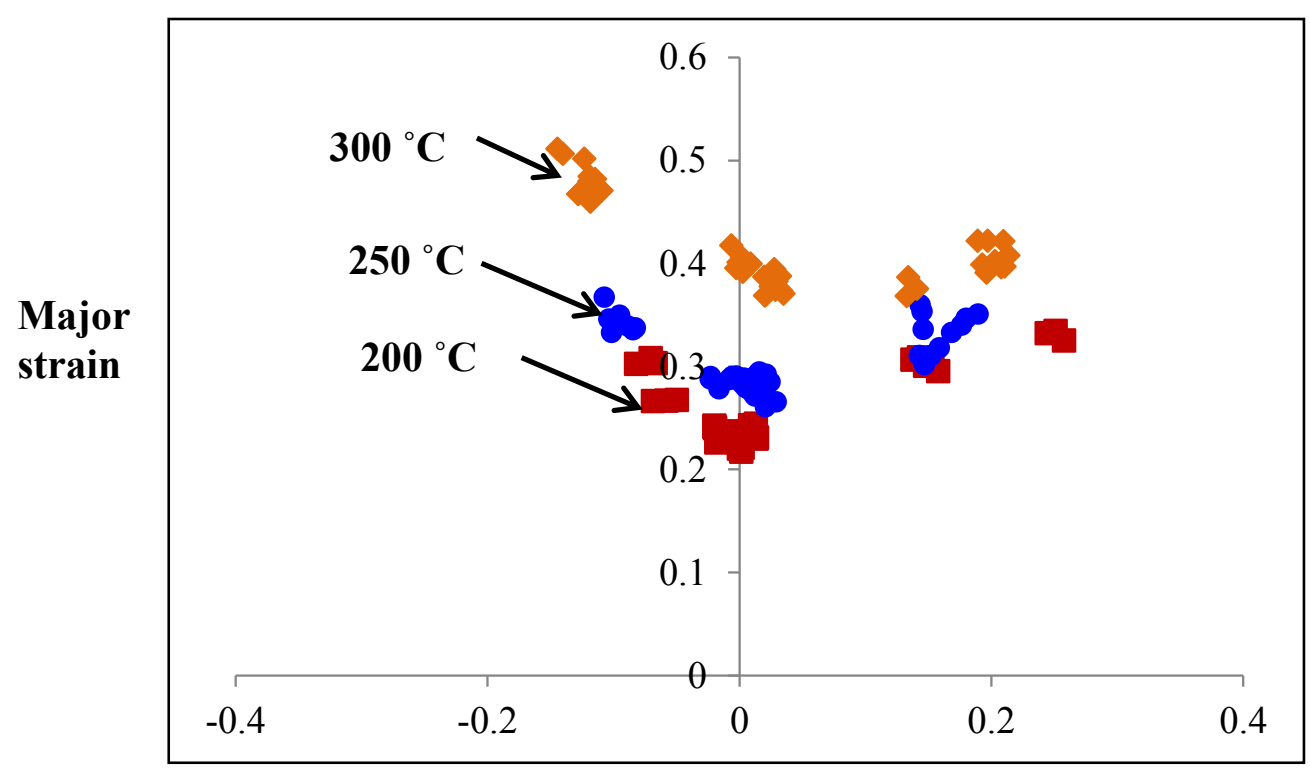




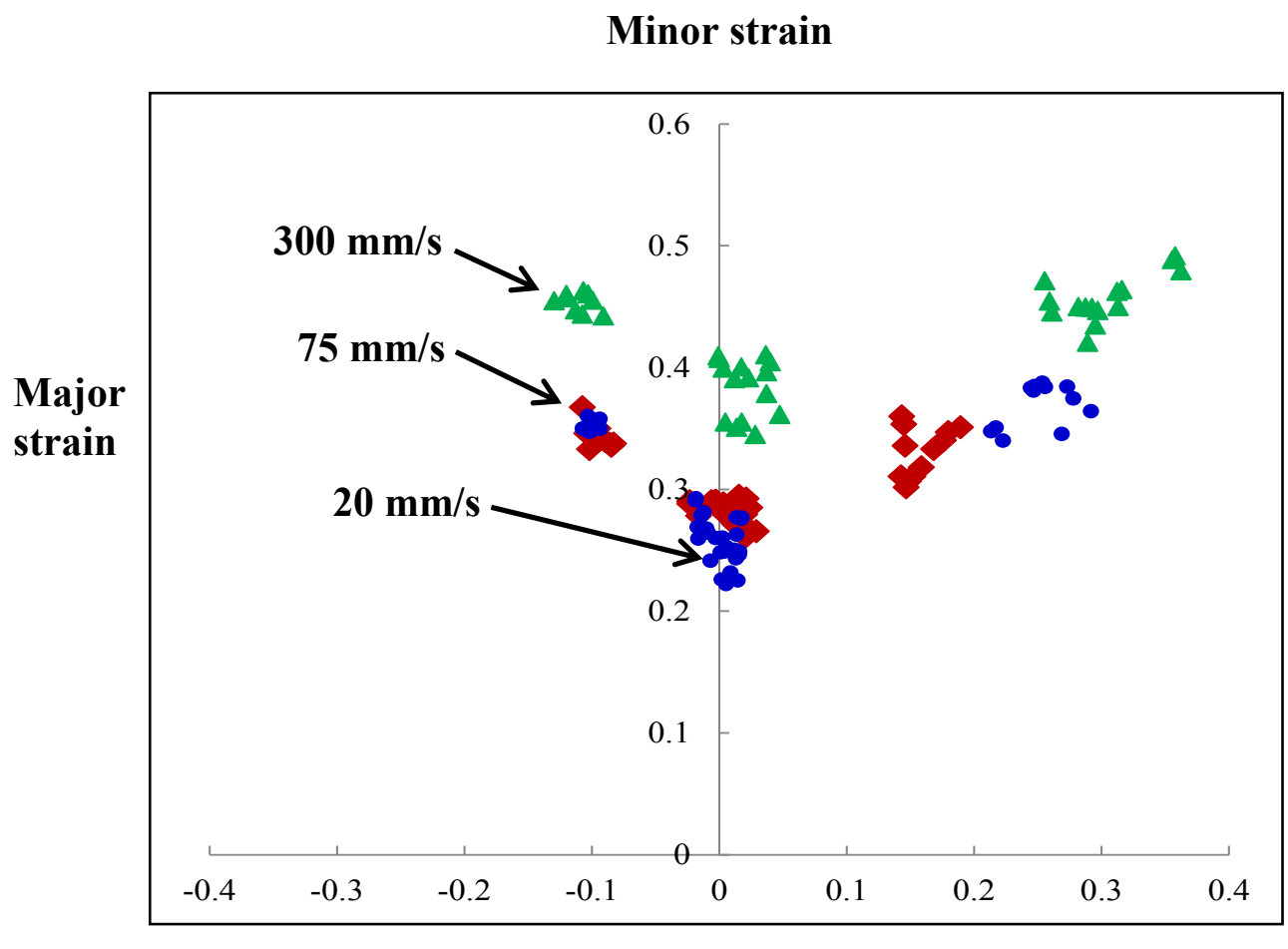

Minor strain

Figure 5. Experimental FLDs for (a) different temperatures at a forming speed of $75 \mathrm{~mm} / \mathrm{s}$ and (b) different forming speeds at a temperature of $250^{\circ} \mathrm{C}$.

\subsection{Material constitutive model}

In warm forming processes, strain rate varies dynamically with both time and location in a work-piece. It is well known that the formability of a metal sheet is a function of strain rate and temperature, thus current FLCs, which are based on fixed values of strain rate cannot be used directly to predict the forming limit of sheet metal in warm forming $[17,19]$.

Lin et al., 2014 and Mohamed et al., 2014 [17, 19] developed a set of plane-stress continuum damage mechanics unified viscoplastic constitutive equations for AA5754. Based on uniaxial 
tensile and formability tests, the continuum damage mechanics stress-based unified constitutive equations (Equations 1 to 6 ) were calibrated.

$$
\begin{aligned}
& \therefore \quad\left(\frac{\sigma /(1-\omega)-R-k}{K}\right)^{n} \\
& \therefore \quad 2 S . \\
& \text { i. } \ldots r^{-0.5} i^{\circ} \\
& \left.\dot{i}-i^{-} \bar{\rho}\right)\left.\right|_{i} \cdot \\
& \sigma_{i j}=(1-\omega) D_{i j k l}\left(\varepsilon_{i j}-\varepsilon_{i j}^{p}\right)
\end{aligned}
$$

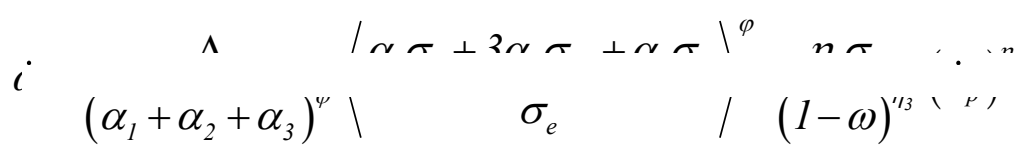

Where $\dot{\varepsilon}_{e}^{p}$ in Equation (1) is the plastic strain rate which is formulated using the traditional power law. The evolution of material hardening, $R$, is given by Equation (3), which is a function of normalised dislocation density, defined as $\bar{\rho}=\left(\rho-\rho_{0}\right) /\left(\rho_{m}-\rho_{0}\right)[20,21]$, where $\rho_{0}$ is the dislocation density for the virgin material (the initial state), and $\rho_{m}$ is the maximum (saturated) dislocation density that the material could have. Thus $\rho$ varies from $\rho_{0}$ to $\rho_{m}$, and normalized dislocation density, $\bar{\rho}$, varies from 0 to 1 . The parameters $K, k, B, E, C, \eta_{1}, \eta_{2}, \eta_{4}$, $A, n, \varphi$ and $\Delta$ are temperature-dependent material constants [22, 23]. Equations in Table 2 represent the temperature-dependent parameters. 
$D_{i j k l}$ is the plane stress elastic stiffness matrix of the material. The multiaxial damage Equation

(6) comes from the uniaxial form with consideration of the multiaxial stress-state effect. $\alpha_{1}$, $\alpha_{2}$ and $\alpha_{3}$ are used to calibrate the effect of maximum principal stress, hydrostatic stress and effective stress on damage evolution respectively. If $\alpha_{1}$ or $\alpha_{2}$ or $\alpha_{3}$ is zero, the implication is that the particular stress has no contribution to the damage process. The symbol $\varphi$ represents a parameter, which controls the effect of multi-axial stress values and their combination on damage evolution, thus determining formability. Symbol $\Delta$ is for a correction factor to unify for the different strain values measured by uniaxial tensile tests and formability tests $[17,19]$.

Data from uniaxial tensile tests and dome forming tests at different temperature and different strain rates were used to calibrate the model and the optimised constants were obtained and shown in Table 3. The strain rate used for FLC model is the average value calculated from the punch speed and the maximum strain value. Figure 6 shows the comparison of experimental (symbols) and computed (solid curves) stress-strain relationships for different strain rates at different temperatures which demonstrate a good agreement between the model predictions and experimental results. The prediction of FLCs is shown as solid curves in Figure 7, which also show a good agreement between the model predictions and experimental results (symbols) for three different forming temperatures at a forming speed of $75 \mathrm{~mm} / \mathrm{s}$, and three different forming speeds at a forming temperature of $250^{\circ} \mathrm{C}$, respectively. When damage parameter reaches 0.9 , it is considered that fracture takes place.

Table 2. Temperature-dependent parameters in the constitutive equation for AA5754.

\begin{tabular}{|l|l|}
\hline$K=K_{01} \exp \left(\frac{-Q_{K 01}}{R T}\right)+K_{02} \exp \left(\frac{-Q_{K 02}}{R T}\right)$ & $k=k_{01} \exp \left(\frac{-Q_{k 01}}{R T}\right)+k_{02} \exp \left(\frac{-Q_{k 02}}{R T}\right)$ \\
\hline$B=B_{01} \exp \left(\frac{-Q_{B 01}}{R T}\right)+B_{02} \exp \left(\frac{-Q_{B 02}}{R T}\right)$ & $E=E_{0} \exp \left(\frac{Q_{E}}{R_{\sigma} T}\right)$ \\
\hline
\end{tabular}




\begin{tabular}{|l|l|}
\hline$C=C_{0} \exp \left(\frac{-Q_{C}}{R_{\sigma} T}\right)$ & $\eta_{1}=\eta_{11} \exp \left(\frac{Q_{\eta 11}}{R T}\right)+\eta_{12} \exp \left(\frac{-Q_{\eta 12}}{R T}\right)$ \\
\hline$\eta_{2}=\eta_{21} \exp \left(\frac{Q_{\eta 21}}{R T}\right)+\eta_{22} \exp \left(\frac{-Q_{\eta 22}}{R T}\right)$ & $\eta_{4}=\eta_{41} \exp \left(\frac{-Q_{\eta 41}}{R T}\right)+\eta_{42} \exp \left(\frac{-Q_{\eta 42}}{R T}\right)$ \\
\hline$A=A_{0} \exp \left(\frac{Q_{A}}{R_{\sigma} T}\right)$ & $n=n_{0} \exp \left(\frac{Q_{n}}{R_{\sigma} T}\right)$ \\
\hline $\boldsymbol{\varphi}=\boldsymbol{p}_{\mathbf{1}}+\frac{\boldsymbol{p}_{\mathbf{2}}}{\boldsymbol{T}}$ & $\boldsymbol{\Delta}=\boldsymbol{p}_{\mathbf{5}} \exp \left(\frac{\boldsymbol{p}_{\mathbf{6}}}{\boldsymbol{T}}\right)+\boldsymbol{d}_{\mathbf{1}} \exp \left(\frac{\boldsymbol{d}_{\mathbf{2}}}{\dot{\boldsymbol{i}}}\right)^{\boldsymbol{d}_{3}}$ \\
\hline
\end{tabular}

Table 3. Material constants in the unified viscoplastic CDM constitutive equation for AA5754.

\begin{tabular}{|l|l|l|l|l|l|}
\hline$K_{l}(\mathrm{MPa})$ & $Q_{K 1}(\mathrm{~J} / \mathrm{mol})$ & $K_{2}(\mathrm{MPa})$ & $Q_{K 2}(\mathrm{~J} / \mathrm{mol})$ & $k_{1}(\mathrm{MPa})$ & $Q_{k 1}(\mathrm{~J} / \mathrm{mol})$ \\
\hline $3.53 \times 10^{2}$ & $1.74 \times 10^{3}$ & $-3.62 \times 10^{2}$ & $3.68 \times 10^{3}$ & $1.17 \times 10^{2}$ & $1.09 \times 10^{3}$ \\
\hline$k_{2}(\mathrm{MPa})$ & $Q_{k 2}(\mathrm{~J} / \mathrm{mol})$ & $B_{1}(\mathrm{MPa})$ & $Q_{B 1}(\mathrm{~J} / \mathrm{mol})$ & $B_{2}(M P a)$ & $Q_{B 2}(\mathrm{~J} / \mathrm{mol})$ \\
\hline$-7.17 \times 10^{2}$ & $1.21 \times 10^{4}$ & $5.79 \times 10^{2}$ & $7.69 \times 10^{2}$ & $-1.02 \times 10^{3}$ & $4.81 \times 10^{3}$ \\
\hline$E_{0}(\mathrm{MPa})$ & $Q_{E}(\mathrm{~J} / \mathrm{mol})$ & $C_{0}\left(\mathrm{~s}^{-1}\right)$ & $Q_{C}(\mathrm{~J} / \mathrm{mol})$ & $\eta_{11}$ & $Q_{\eta_{l l}}$ \\
\hline $3.86 \times 10^{4}$ & $1.47 \times 10^{3}$ & $7.24 \times 10^{9}$ & $1.09 \times 10^{5}$ & 1.63 & $6.72 \times 10^{2}$ \\
\hline$\eta_{12}$ & $Q_{\eta_{l 2}}$ & $\eta_{21}$ & $Q_{\eta_{21}}$ & $\eta_{22}$ & $Q_{\eta_{22}}$ \\
\hline-2.47 & $6.82 \times 10^{3}$ & 1.98 & $6.79 \times 10^{2}$ & -3.71 & $5.29 \times 10^{3}$ \\
\hline$\eta_{3}$ & $\eta_{41}$ & $Q_{\eta_{41}}$ & $\eta_{42}$ & $Q_{\eta_{42}}$ & $A_{0}$ \\
\hline 1.08 & 18.8 & $1.74 \times 10^{4}$ & -10.9 & $1.61 \times 10^{4}$ & 1.44 \\
\hline$Q_{A}$ & $n_{0}$ & $Q_{n}$ & $p_{1}$ & $p_{2}$ & $p_{3}$ \\
\hline $1.15 \times 10^{2}$ & 5.07 & $1.69 \times 10^{3}$ & -6.00 & $6.30 \times 10^{3}$ & 0.39 \\
\hline$p_{4}$ & $d_{1}$ & $d_{2}$ & $d_{3}$ & & \\
\hline $2.14 \times 10^{2}$ & -3.83 & $3.9 \times 10^{-3}$ & 0.91 & & \\
\hline
\end{tabular}



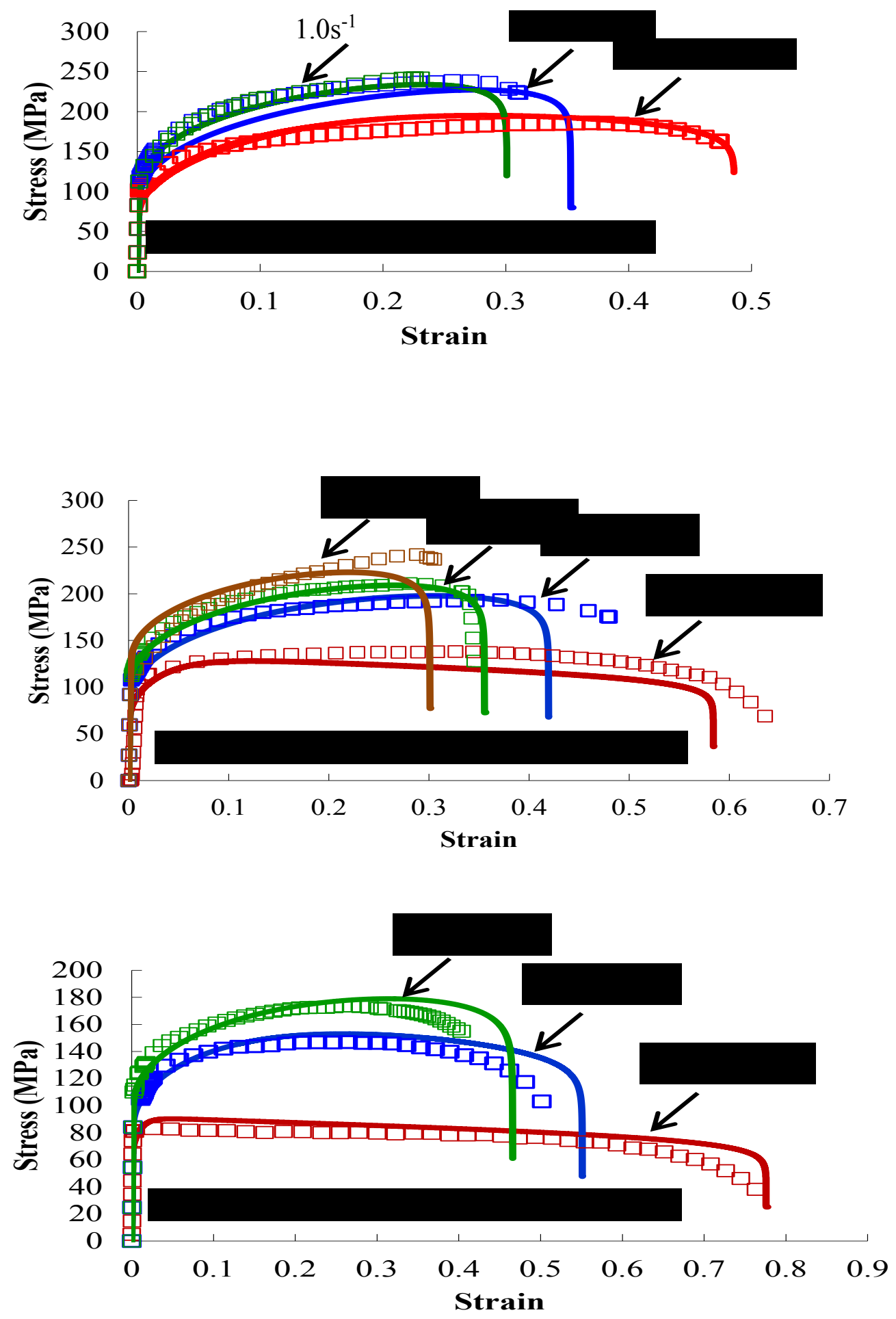

Figure 6. Comparison of experimental (symbols) and computed (solid curves) stress-strain relationships for different strain rates at different temperatures. 

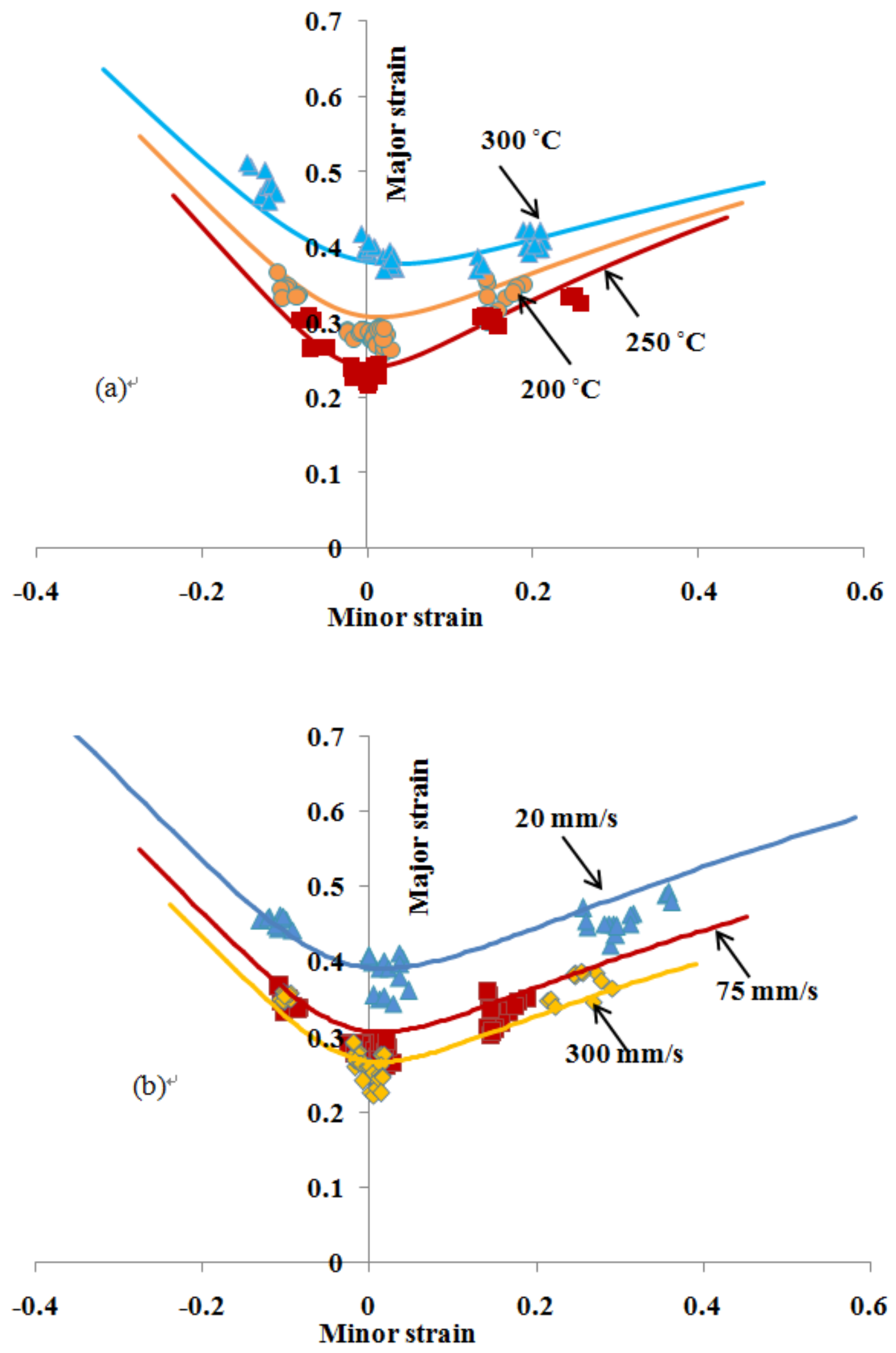

Figure 7. Comparison of experimental (symbols) and computed (solid curves) FLDs for (a) different temperatures at a forming speed of $75 \mathrm{~mm} / \mathrm{s}$ and (b)different forming speeds at a temperature of $250^{\circ} \mathrm{C}$. 


\section{Development of finite element model for formability test}

FE simulations of the dome formability test were conducted using the explicit FE code Dynaform/Ls-Dyna and the plane stress deformation mode. The viscoplastic constitutive equations for deformation and damage, as well as the equations for the temperature-depended parameters, were embedded via the UMAT subroutine and coded using FORTRAN. A schematic diagram of the coupled thermo-mechanical model with boundary conditions is shown in Figure 6. The sheet was meshed using four-noded linear thin shell elements, with five elements through the thickness to ensure bending could be captured. Since the plastic anisotropy of AA5754 aluminium alloy is insignificant [3], isotropic material was used in this FE model. A quarter symmetry finite element model is shown in Figure 6. The diameter of the punch was $80 \mathrm{~mm}$. The blank, with a diameter $160 \mathrm{~mm}$ and thickness of $2 \mathrm{~mm}$, is deformed by a semi-spherical punch with diameter of $80 \mathrm{~mm}$, with a fixed top die and moveable lower blank holder with a spring force of $20 \mathrm{kN}$ applied.

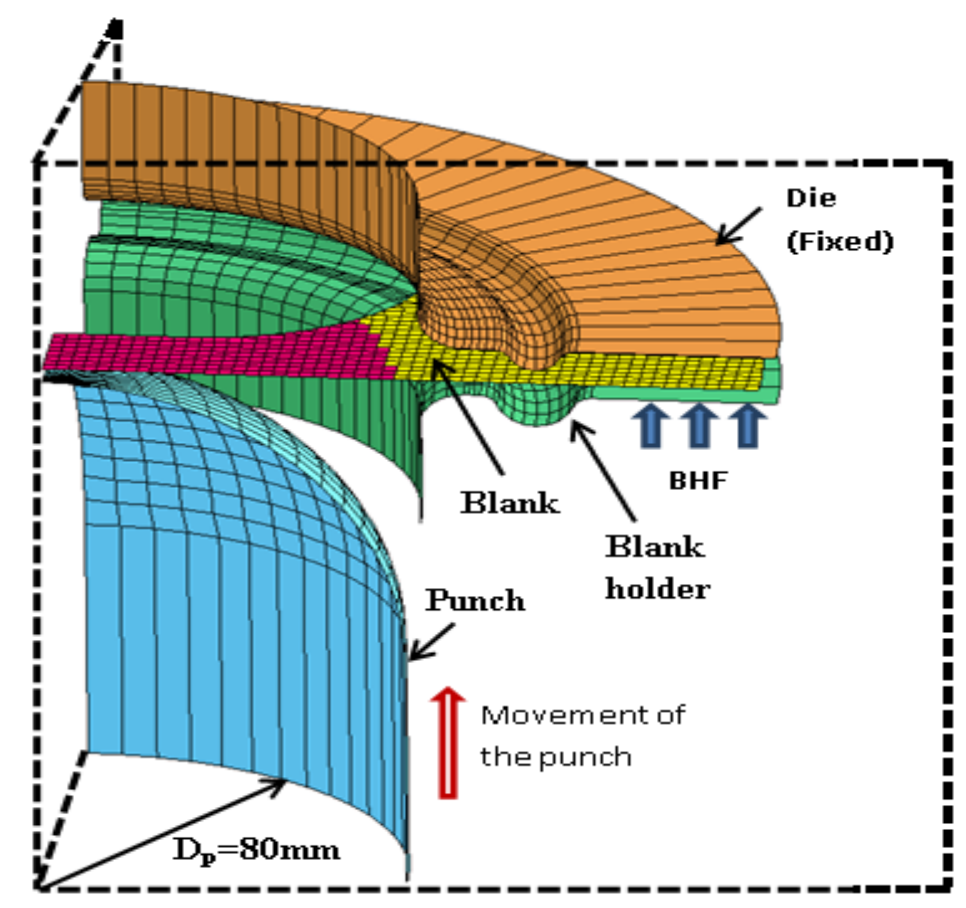

Figure 8.FE model of the dome formability test. 
In the FE model, two different material properties are defined at different locations of the blank. In the region within the diameter of $80 \mathrm{~mm}$, shown by the red area in Figure 8, work-piece properties are defined by the CDM constitutive equations. In the region clamped by the blank holders, shown by the yellow area in Figure 6, the damage parameter is removed, since the deformation and damage accumulation in the doming region is the focus of this study.

The first step in the FE process modelling procedure was application of the boundary conditions. At the start of the simulation, the punch moves toward the sheet and first contact occurs between the sheet and blank holders. A blank holder pressure of $20 \mathrm{kN}$ is applied to ensure no material is drawn in during the process. The forming speed was $75 \mathrm{~mm} / \mathrm{s}$, and blank temperature was $250{ }^{\circ} \mathrm{C}$. There are many available methods to determine the friction coefficient between the work-piece and tools [23]. At elevated temperature, the friction between the AA5754 blank and the tools is inevitable and the sliding friction coefficient was defined as $0.1[24]$. Since the formability test was conducted under an isothermal condition, it is assumed there is no heat transfer between the blank and the tools. When damage parameter reached 0.9, simulation was terminated.

\section{Results and Discussion}

Figure 9 shows the damage parameter variation with time $t / t_{f}$ for different strain paths, where $t$ represents current time and $t_{f}$ represents the final time. The damage parameter is zero (no damage) at the beginning of deformation, and remains zero until damage is initiated, at which point the damage parameter, as calculated by the viscoplastic damage equations, increased with time. For these three strain paths, there is a significant increase of the damage parameter before failure. It is can be seen that the damage evolutions are different for different strain paths, which is attributed to the different stress states for these three strain paths at a certain time. 


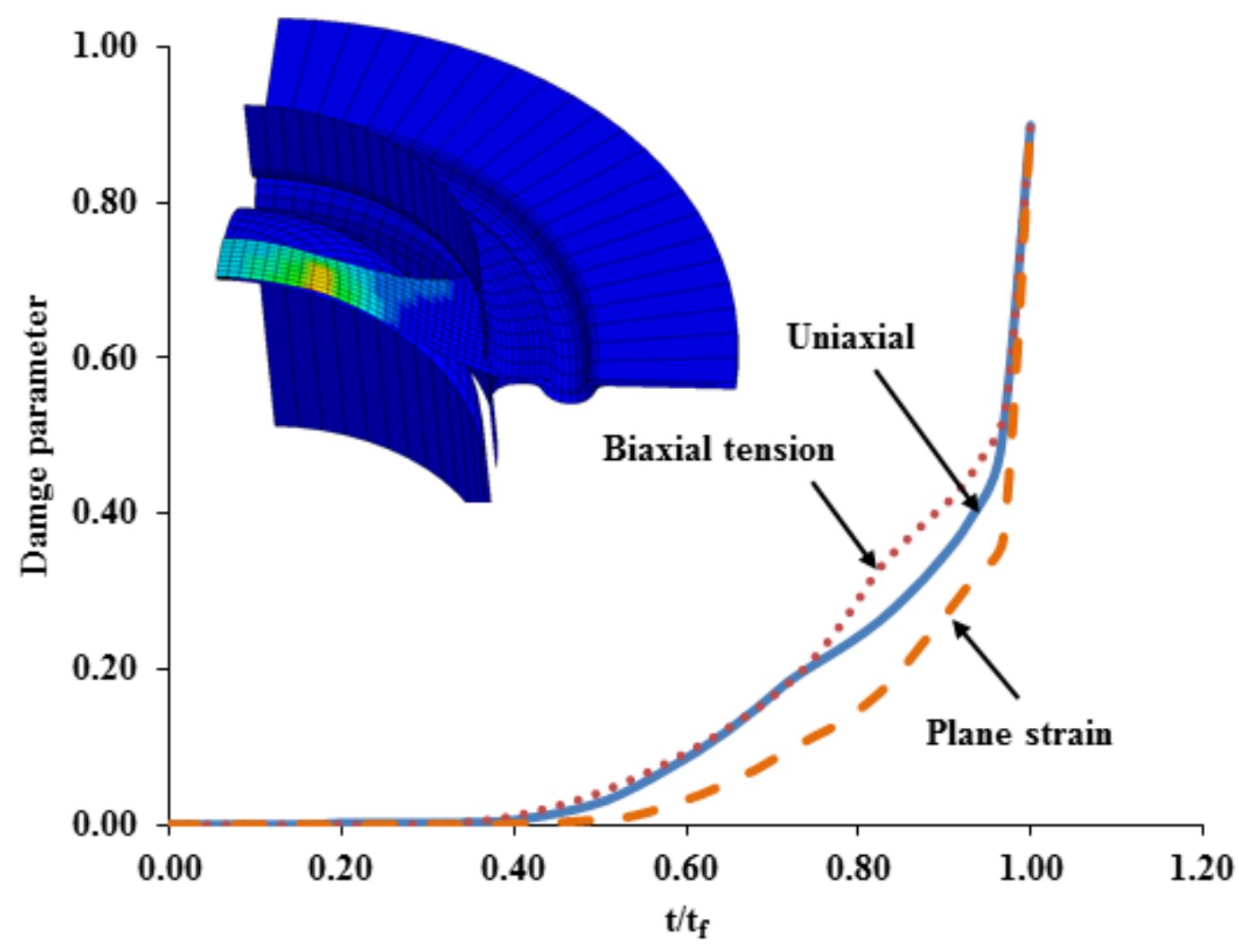

Figure 9. Prediction of damage parameter at the fracture locations for different strain paths, (Forming speed of $75 \mathrm{~mm} / \mathrm{s}$, temperature of $250^{\circ} \mathrm{C}$ )

Figure 10shows FE simulation results for different strain paths at a forming speed of $75 \mathrm{~mm} / \mathrm{s}$ and temperature of $250^{\circ} \mathrm{C}$. It can be observed that ductile failure is initiated at the location of localised necking. The prediction major strains at the failure are in good agreements of experiment results in the uniaxial, biaxial and plane strain state. If there was no friction, the maximum deformation should be in the centre of the specimen. Due to the friction between the blank and tools, the deformation in the centre was hindered by friction; therefore, the maximum strain occurs at a distance from the centre of the specimen in three strain state tests. With regard to the test-piece 1, i.e. uniaxial strain state, the maximum major strain in the area near the centre is around 0.33 ; with regard to test-piece 2 , i.e. plane stress state, the maximum major strain is around 0.3 ; with regard to the test-piece 3 , i.e. biaxial strain state, the maximum major strain is around 0.2. The location of fracture is the same as in simulation and experiment, for three 
strain states, respectively. Qualitatively the simulations are in good agreement with the experiments, which indicates that the damage equation is correctly formulated and implemented.

The largest plastic strain indicates the location of maximum thinning. Notably, the plastic strain is low in the mid-height circumferential region. In these three cases, the plastic strain is low at the location of the drawing bead, indicating that very little drawing of material through the clamping location occurs in the simulations.

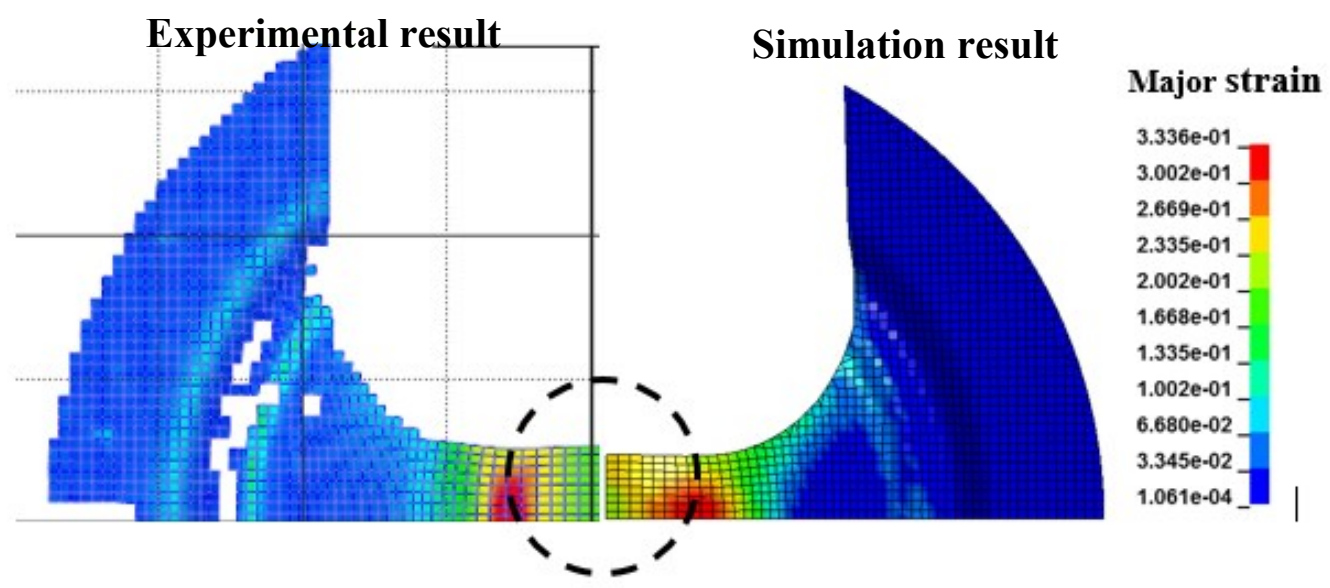

(a) Test-piece 1

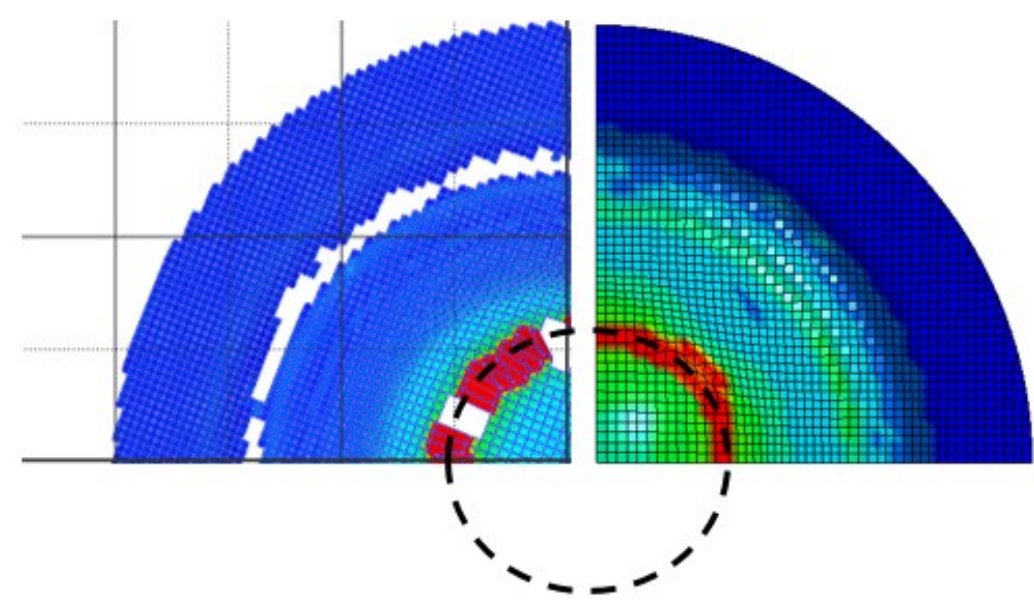

Major strain

$3.000 \mathrm{e}-01$

2.710e-01

2.420e-01

$2.130 \mathrm{e}-01$

$1.840 \mathrm{e}-01$

$1.550 \mathrm{e}-01$

1.260e-01

9.699e-02

6.799e-02

$3.899 \mathrm{e}-02$

$9.984 \mathrm{e}-03$

(b) Test-piece 2 


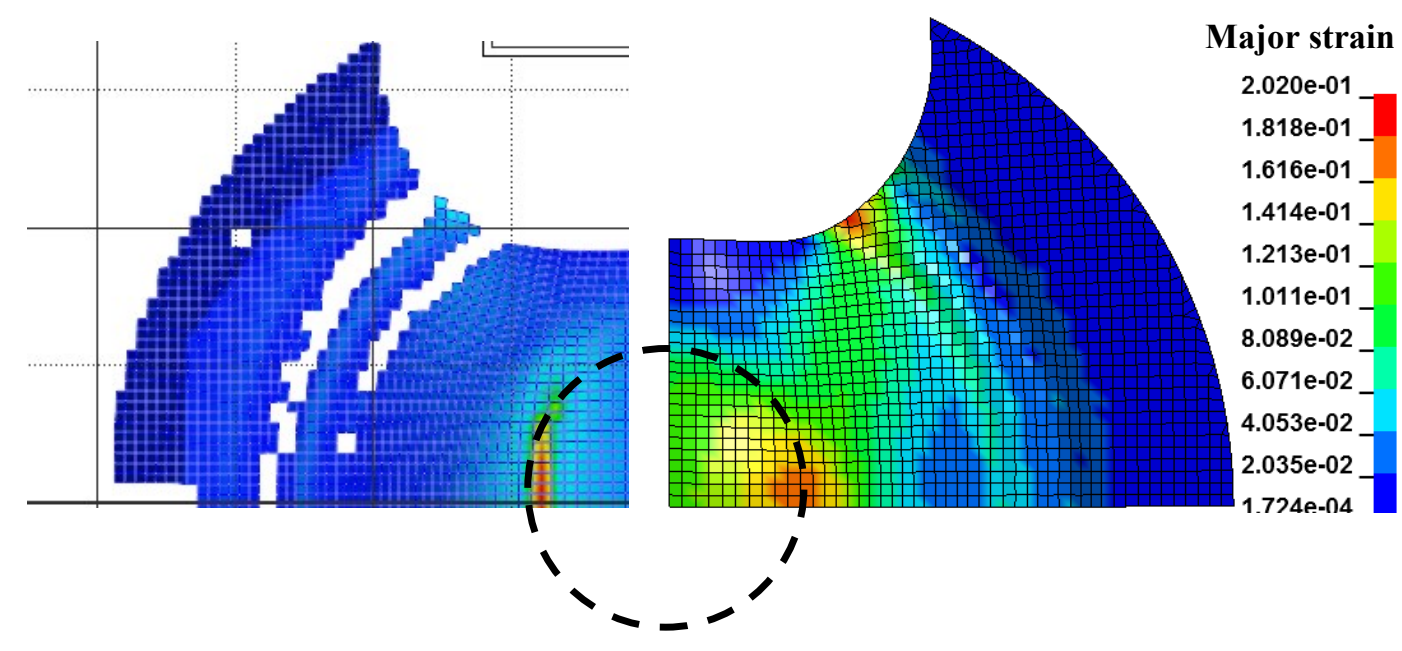

(c) Test-piece 3

Figure 10. FE simulation and experimental results for different test-pieces. Forming speed: $75 \mathrm{~mm} / \mathrm{s}$, temperature: $250^{\circ} \mathrm{C}$.

Comparisons of major strain distribution from experiment with FE simulation of the CDM model at times interval, $\mathrm{t} / \mathrm{t}_{\mathrm{F}}=0.3,0.6$ and 1.0 are shown in Figure 11 . The speed is $75 \mathrm{~mm} / \mathrm{s}$ and the forming temperature is $250^{\circ} \mathrm{C}$. It can be seen that good agreement between results from the CDM model and experimental observations in terms of the thickness distribution and damage location for Test-piece 1 and 2. However for Test-piece 3, the difference of the major strain between the numerical and experimental results may be attributed to the fact that a constant friction coefficient was used in the FE model, but the friction situation was changed in the experiment [3]. At $\mathrm{t} / \mathrm{t}_{\mathrm{f}}=0.3$, the punch starts to stretch the test-piece up from the center and cause little major strain in the center of the sample. Further increasing of the punch stroke to a time ratio $\left(\mathrm{t} / \mathrm{t}_{\mathrm{f}}=0.6\right)$ and due to friction between the sample and the punch, the max major strain is moved away from the center. At the end of the simulation and experiment failure takes place at expectable and at acceptable distance from the center. 


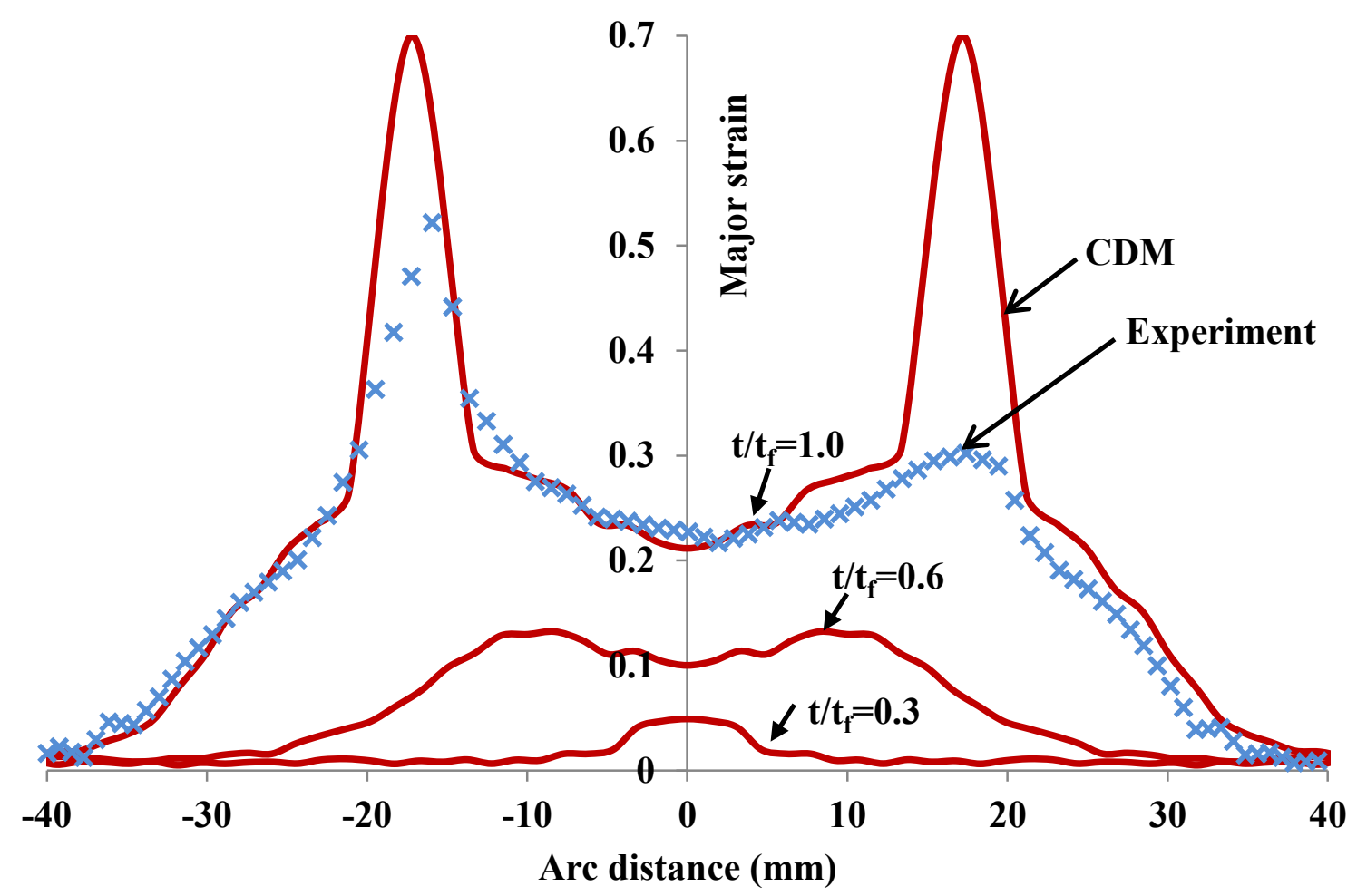

(a) Test-piece 1

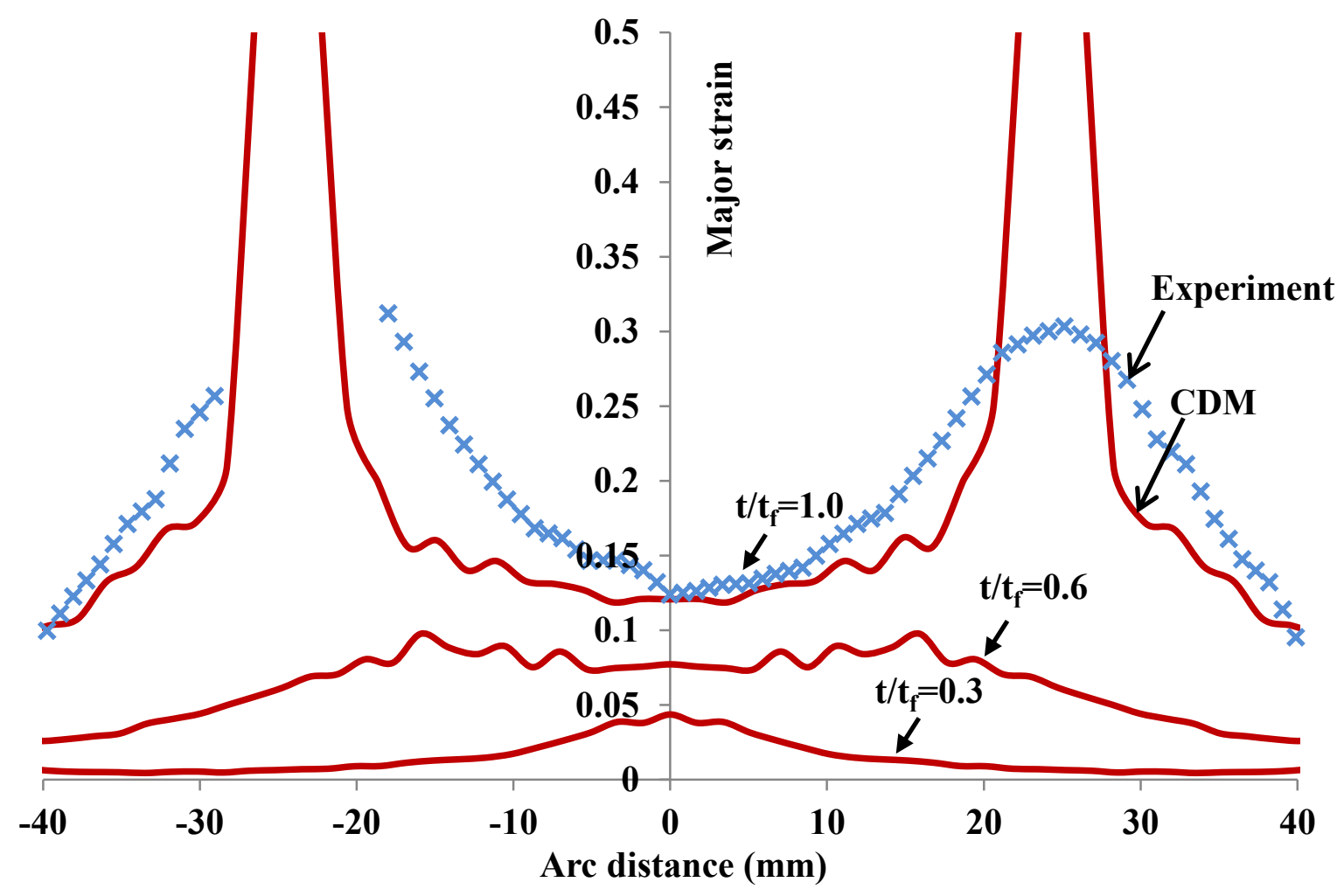

(b) Test-piece 2 


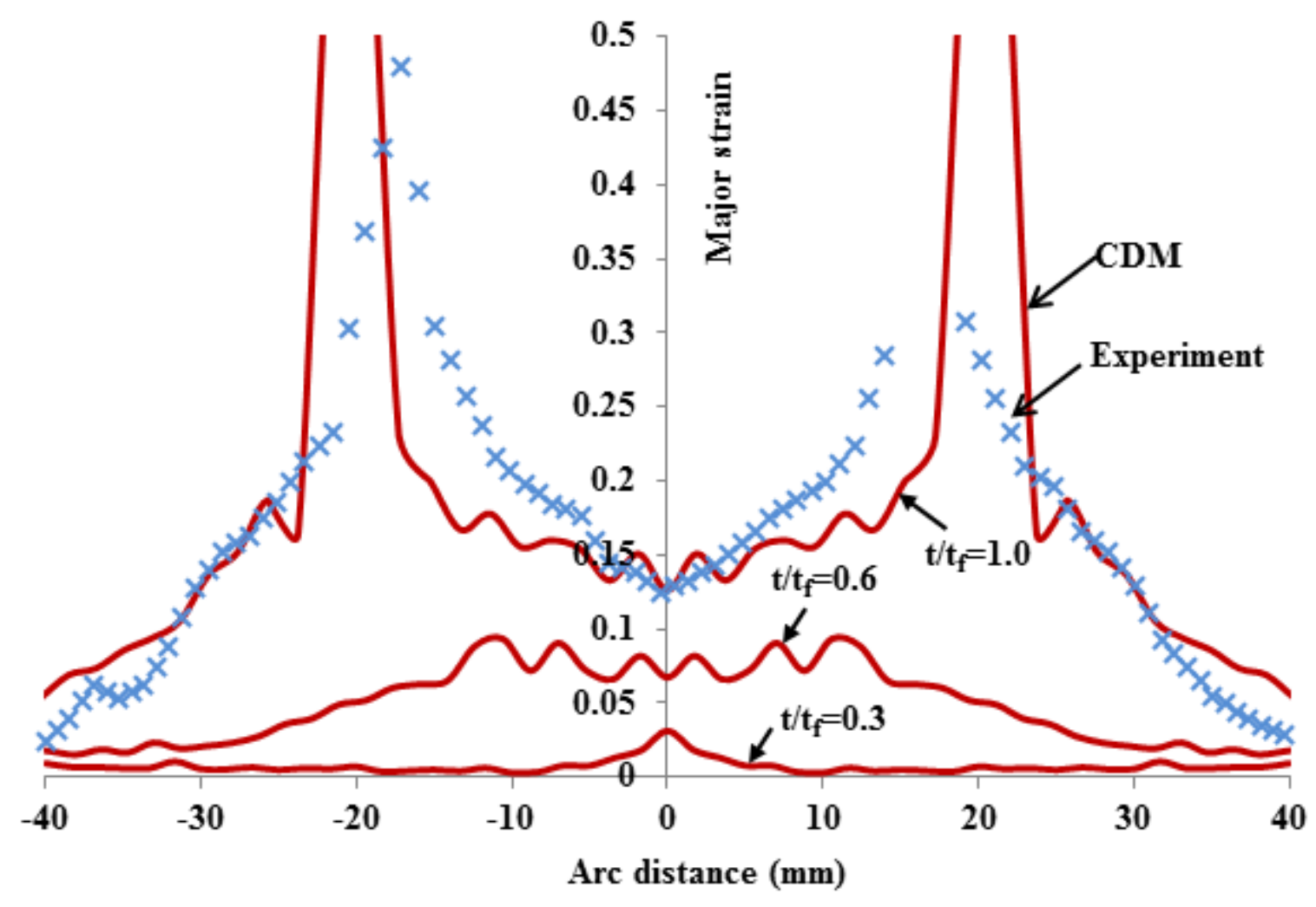

(c) Test-piece 3

Figure 11. Major strain distribution with arc distance for test-piece 1 at different time. Forming speed is $75 \mathrm{~mm} / \mathrm{s}$, temperature is $250^{\circ} \mathrm{C}$.

\section{Conclusions}

A set of continuum damage mechanics (CDM)-based constitutive equations were developed and calibrated for AA5754. The equations were calibrated using two different sets of experiments; first the isothermal uniaxial data at different temperature and strain rates and secondly FLCs for different temperatures and different forming rates. The model was then validated by comparing FE model predictions to experimental results from dome forming tests. The close agreement between the predictions and observations of crack locations and major strain distribution indicates that the calibrated equations have the correct physical scaling and can be used to accurately model the viscoplastic flow and damage accumulation of AA5754 
until failure. It is considered that the CDM model can be used to predict the formability of AA5754 during various warm forming processes.

\section{Acknowledgements}

The authors would like to thank Dr Zhutao Shao and Dr Liliang Wang in Imperial College London for the experimental work. Q.B. would like to thank 'Science Fund for Creative Research Groups of NSFC (51321004)’.

\section{References}

[1] Polmear, I. J. (1995) Light Alloys-Metallurgy of the Light Metals, 3rd, London, pp.337342.

[2] Mohamed, M. Foster, A. Lin, J. (2008) 'Solution heat treatment in HFQ process', Steel Research International, 79-11-VII, pp.160-167.

[3] Laurent, H. Coër, J. Manach, P. Y. Oliveira, M. C. Menezes, L. F. (2015) 'Experimental and numerical studies on the warm deep drawing of an Al-Mg alloy', International Journal of Mechanical Sciences, 93, pp. 59-72.

[4] Mohamed, M. S. Foster, A. D. Lin, J. Balint, D. S. Dean, T. A. (2012) 'Investigation of deformation and failure features in hot stamping of AA6082: experimentation and modelling', International Journal of Machine Tools and Manufacture 53(1), pp. 27-38.

[5] Garrett, R.P. Lin, J. Dean, T.A. (2005) 'An investigation of the effects of solution heat treatment on mechanical properties for AA 6xxx alloys: experimentation and modelling', International Journal of Plasticity 21(8), pp.1640-1657.

[6] Mohamed, M. Foster, A. Lin, J. (2008) 'Solution heat treatment in HFQ process', Steel Research International, 79-11-VII, pp.160-167.

[7] Martins, J. M. P., Alves, J. L., Neto, D. M., Oliveira, M. C., Menezes, L. F. (2015) 'Numerical analysis of different heating systems for warm sheet metal forming', The International Journal of Advanced Manufacturing Technology, 83(5), pp. 1-13.

[8] Banabic, D. Lazarescu, L. Paraianu, L. Ciobanu, L. Nicodim, I. Comsa, D.S. (2013) 'Development of a new procedure for the experimental determination of the Forming Limit Curves', CIRP Annals - Manufacturing Technology, 62(1), pp. 255-258.

[9] Li, D., Ghosh A.K. (2004) 'Biaxial warm forming behaviour of aluminium sheet alloys', Journal of Materials Processing Technology, 145(3), pp. 281-293. 
[10] Keeler, S. P. (1965) 'Determination of forming limits in automotive stampings', SAE Technical Paper 650535, doi:10.4271/650535.

[11] Martins, P. A. F., Bay, N., Tekkaya, A. E., Atkins, A. G. (2014) 'Characterization of fracture loci in metal forming', International Journal of Mechanical Sciences, 83, pp.112123.

[12] Marciniak, Z. Kaczynski, K. Pokora, T. (1973) 'Influence of the plastic properties of a material on the forming limit diagram for sheet metal in tension', International Journal Mechanical Science, 15, pp.789-805.

[13] Nakajima, K. Kikuma, T. Asaku, K. (1968) 'Study on the formability of steel sheet', Yawata Technical Report 264.

[14] Abspoel, M. Atzema, E. H. Droog, J. M. M. Khandeparkar, T. Scholting, M. E. Schouten, F. J. Vegter, H. (2011) 'Inherent influence of strain path in Nakajima FLC tests', Proceedings of the 8th IDDRG Conference, Mumbai, India, pp.1-9.

[15] Goodwin, G. M. (1968) 'Application of strain analysis to sheet metal forming problems in the press shop', Metall, Italiana, 60, pp.764-74.

[16] Shi, Z., Lin, J., Dean, T., Balint, D., Stanton, M., Watson, D., (2012), An Investigation, Using Standard Experimental Techniques, to Determine FLCs at Elevated Temperature for Aluminium Alloys, in 3rd International Conference on New Forming Technology, Harbin, China.

[17] Lin, J. Mohamed, M. Balint, D. Dean, T.A. (2014) 'The Development of CDM-based theories for predicting FLD for hot stamping applications', International Journal of Damage Mechanics 23(5), pp.684-701.

[18] Saboori, M., Champliaud, H., Gholipour, J., Gakwaya, A., Savoie, J., \& Wanjara, P. (2015) 'Extension of flow stress-strain curves of aerospace alloys after necking', The International Journal of Advanced Manufacturing Technology, 83(1), pp. 1-11.

[19] Mohamed, M. Lin, J. Foster, A. Dean, T. Dear, J. (2014) 'A New Test Design for Assessing Formability of Materials in Hot Stamping', Procedia Engineering, 81, pp.16891694.

[20] Lin, J. Cheong, B. H. Yao, X. (2002) 'Universal multi-objective function for optimising superplastic-damage constitutive equations', Journal of Materials Processing Technology, 125-126, pp.199-205.

[21] Lin, J. Dean, T.A. (2005) 'Modelling of microstructure evolution in hot forming using unified constitutive equations', Journal of Materials Processing Technology 167(2-3), pp.354-362. 
[22] Mohamed, M. Lin, J. Wang, L. Balint, D. (2010) 'Hybrid forming processes for production of lightweight high strength automotive panel parts', International Heat Treatment \& Surface Engineering, (4), pp.160-165.

[23] Ghassemali, E. Tan, M. J. Lim, S. C. V. Wah, C. B. Jarfors, A. E. W. (2014) 'Experimental and simulation of friction effects in an open-die microforging/extrusion process', Journal of Micro and Nano-Manufacturing, 2(1), 011005.

[24] Foster, A. Mohamed, M. Lin, J. Dean, T. A. (2008) 'An investigation of lubrication and heat transfer for a sheet aluminium Heat, Form-Quench (HFQ) process', Steel Research International, 79-11-VII, pp.133-140. 